\title{
On relation between J-integral and heat energy dissipation at the crack tip in stainless steel specimens
}

\author{
G. Meneghetti, M. Ricotta \\ University of Padova, Department of Industrial Engineering, Via Venezia, 1, 35131 Padova, Italy \\ giovanni.meneghetti@unipd.it, http://orcid.org/0000-0002-4212-2618 \\ mauro.ricotta@unipd.it, bttp:/ /orcid.org/0000-0002-3517-9464
}

\section{G. Pitarresi}

University of Palermo, Dipartimento di Ingegneria, Viale delle Scienze, 90128 Palermo, Italy giuseppe.pitarresi@unipa.it, bttp://orcid.org/0000-0002-5713-1840

\begin{abstract}
In this paper, an experimental procedure to evaluate the elasticplastic J-integral at the tip of a fatigue crack is presented. According to this new approach, the elastic component of the J-integral is derived from Thermoelastic Stress Analysis, while the plastic component of the J-integral is derived from the heat energy loss. An analytical link is proposed to apply this new experimental technique. Therefore, the elastic-plastic J-integral range was evaluated starting from infrared temperature maps measured in situ during crack propagation tests of AISI 304L stainless steel specimens. It was found that the range of the infrared thermography-based J-integral correlated well the crack growth data generated in small as well as large scale yielding conditions. Finally, the experimental values of the J-integral were successfully compared with the corresponding numerical values obtained from elasticplastic finite element analyses.
\end{abstract}

KEYwORDS. Fracture Mechanics; Crack tip plasticity; Thermoelastic Stress Analysis; Energy methods; J-integral.

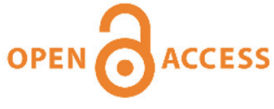

Citation: Meneghetti, G., Ricotta, M., Pitarresi, G., On relation between J-integral and heat energy dissipation at the crack tip in stainless steel specimens, Frattura ed Integrità Strutturale, 49 (2019) 82-96.

Received: 29.04.2019

Accepted: 01.05.2019

Published: 01.07.2019

Copyright: (C) 2019 This is an open access article under the terms of the CC-BY 4.0, which permits unrestricted use, distribution, and reproduction in any medium, provided the original author and source are credited.

\section{INTRODUCTION}

$\mathrm{T}$ he development of infrared cameras having increased performances in terms of thermal sensitivity, spatial resolution and frame rate has given impulse to several experimental investigations involving the evaluation of temperature in Facture Mechanics problems. Some fields where infrared cameras have allowed an enhanced insight include: the investigation of local heating at the crack tip [1-3], the assessment of crack propagation based on the hysteresis energy [415], the influence of thermal effects on stress intensity factors [16,17], the evaluation of the plastic zone size and its correlation to the heat energy dissipation at the crack tip [18-26] and the correlation of energy dissipation at the crack tip with the J-integral [27-29]. 
Recently [29], an experimental method and an analytical expression were formalized to evaluate the Rice's J-integral [30] during a fatigue test. The experimental method is based on full-field temperature measurements around the tip of the fatigue crack, by using an infrared camera having high temperature and spatial resolution. The proposed methodology evaluates separately the elastic and plastic contributions to the total J-integral. The elastic component is calculated from the experimental evaluation of the mode I Stress Intensity Factor by means of Thermoelastic Stress Analysis (TSA) [31,32]. The plastic component of $\mathrm{J}$ is estimated from the specific heat loss per cycle averaged over a control volume of material; the underlying engineering assumption is that the plastic strain hysteresis energy per cycle is fully converted into heat. The proposed methodology was applied successfully to fatigue crack growth data generated from push-pull, axial fatigue tests of 4-mm-thick hot rolled AISI 304L stainless steel specimens.

In this paper, after a brief description of the theoretical aspects, the experimental procedure for the evaluation of the elastic and plastic component of the J-integral will be presented and discussed.

\section{THEORETICAL BACKGROUND}

Heat dissipation at the crack tip

7 he first law of thermodynamics can be written in terms of power averaged over one loading cycle [29] (dot symbol indicates the time derivative):

$$
\dot{\bar{U}}=\dot{\bar{W}}+\dot{\bar{Q}}
$$

where $\dot{\bar{U}}$ is the internal energy rate, $\dot{\bar{W}}$ the plastic strain energy rate and $\dot{\bar{Q}}$ the heat energy rate exchanged by a unit volume of material. The first law of thermodynamics, written in terms of energy averaged over one loading cycle, is shown in Fig. 1 , which defines the positive quantities involved.

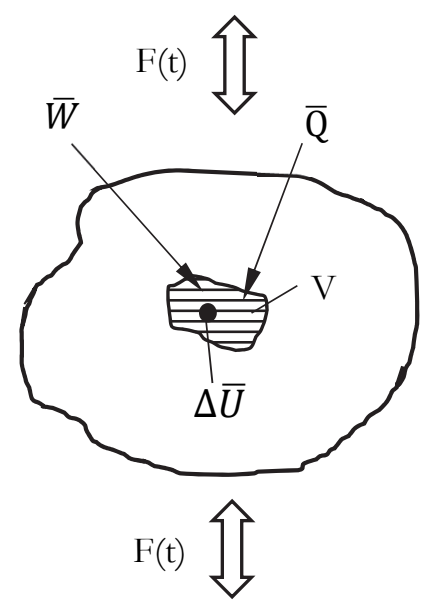

Figure 1: Energy balance for a material undergoing fatigue loadings.

The specific heat loss $\bar{Q}$ can now be averaged in a volume $\mathrm{V}_{\mathrm{c}}$ surrounding the tip of the crack (see Fig. 2), according to the following expression [26]:

$$
\bar{Q}^{*}=\frac{1}{V_{c}} \int_{V_{c}} \bar{Q} \cdot d V \Rightarrow=-\frac{1}{f_{L} V_{c}} \cdot \int_{S_{c d}} \bar{b} \cdot d S
$$

where $\mathrm{f}_{\mathrm{L}}$ is the load test frequency and the heat flux $\bar{b}$ is integrated in the portion of the boundary of $\mathrm{V}_{\mathrm{c}}, \mathrm{S}_{\mathrm{cd}}$, through which heat energy is transferred by conduction according to [26,28]. 


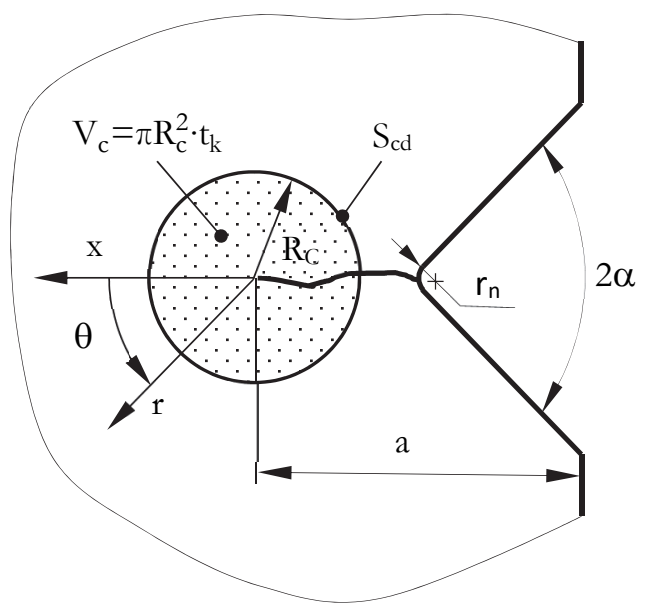

Figure 2: Propagating fatigue crack and the assumed shape of the control volume $V_{c}$ where the heat energy is to be averaged.

The heat flux $\bar{b}$ can be evaluated from the thermal gradients calculated from infrared temperature maps; therefore, referring to a two-dimensional problem, Eqn. (3) can be written as follows [26]:

$$
\bar{Q}^{*}=\left.\frac{1}{f_{L} V_{c}} \cdot \lambda \cdot t_{k} \cdot R_{c} \cdot \int_{-\pi}^{+\pi} \frac{\partial \bar{T}(r, \theta)}{\partial r}\right|_{r=R_{c}} \cdot d \theta
$$

where $\lambda$ is the coefficient of material thermal conductivity, $\mathrm{t}_{\mathrm{k}}$ the specimen thickness and $\bar{T}(r, \theta)$ the average temperature per cycle measured after the thermal equilibrium with surroundings is achieved, as shown in Fig. 3, which reports a typical temperature vs time acquisition at a point inside $V_{c}$ after a fatigue test has started. If the temperature field is monitored by means of an infrared camera, Fig. $3 \mathrm{a}$ is the pixel-by-pixel temperature vs time history and it shows that temperature increases until the mean level stabilizes and the alternating component due to the thermoelastic effect is superimposed (see Fig. $3 \mathrm{~b}$ ). To calculate the average temperature field $\bar{T}(r, \theta)$ in Eqn. (3) let us consider a sampling window taken after thermal equilibrium with the surroundings is achieved (between $t_{s}$ and $t^{*}$ in Fig. $3 a$ ); the average temperature referred to the $i$-th pixel is defined as follows:

$$
T_{m}^{i}=\frac{\sum_{j=1}^{n_{\max }} T_{j}^{i}}{n_{\max }}
$$

where $T_{j}^{i}$ are the temperature data acquired at a sampling rate $\mathrm{f}_{\text {acq }}$ and $\mathrm{n}_{\max }=\mathrm{f}_{\mathrm{acq}} \cdot\left(\mathrm{t}^{*}-\mathrm{t}_{\mathrm{s}}\right)$ is the number of picked-up samples between the start time $t_{s}(j=1)$ and the end time $t^{*}\left(j=n_{\max }\right)$.

\section{J-integral estimations from the temperature field}

In the open literature (see [33], as an example), the Rice's J-integral [30] is adopted as driving force to rationalise crack growth data in small as well as large scale yielding conditions. J can be evaluated by adding its elastic, $\mathrm{J}_{\mathrm{e}}$, and plastic, $\mathrm{J}_{\mathrm{p}}$, contributions [33]:

$$
J=J_{e}+J_{p}
$$

Evaluating the elastic contribution, $\mathrm{J}_{\mathrm{e}}$, is very straightforward since it can be calculated according to Eqn.6a and 6b, for plane stress or plane strain conditions, respectively: 


$$
\begin{aligned}
& J_{\text {max }, \varphi}=\frac{K_{I, \max }^{2}}{E} \\
& J_{\max , \varphi}=\frac{K_{I, \max }^{2}\left(1-v^{2}\right)}{E}
\end{aligned}
$$

$K_{I}$ being the linear elastic stress intensity factor for the same applied external load [33]. The experimental evaluation of the elastic and plastic components of the J-integral starting from infrared thermograms is reported in detail in the next sections.

(a)

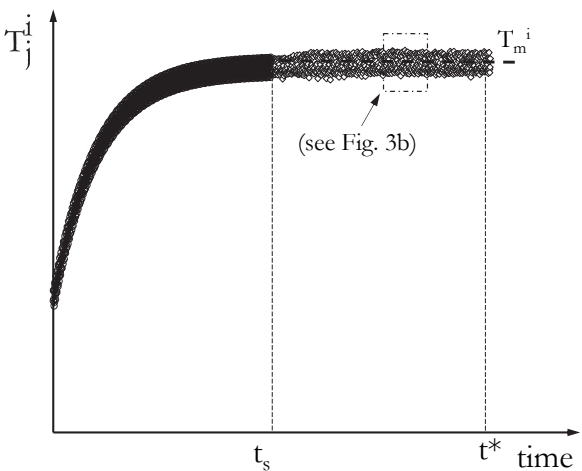

(b)

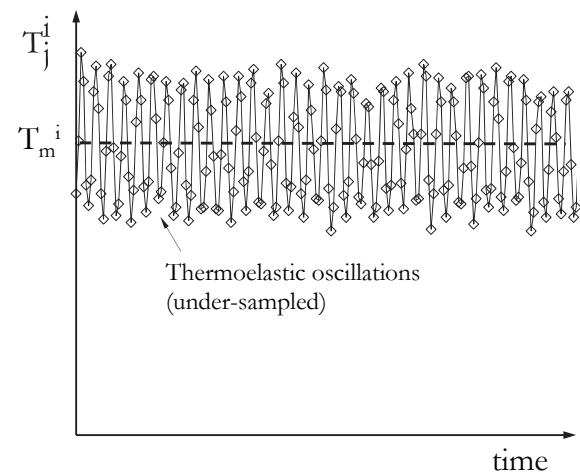

Figure 3: Time-variant temperature for i-th pixel (a) and detailed view (b).

\section{Evaluating Mode I Stress Intensity factor by means of Thermoelastic Stress Analysis}

The Thermoelastic Effect describes the local reversible temperature change, $\Delta \mathrm{T}$, developed by a solid when deformed within its linear elastic regime. According with the first order theory [31], such temperature change is linearly correlated to the inplane first stress invariant through the following relationship:

$$
\Delta T=-T_{0} K_{T H} \Delta \sigma_{i i}
$$

where $\mathrm{T}_{0}$ is the initial material temperature at each thermoelastic acquisition, $\mathrm{K}_{\mathrm{TH}}$ is the material thermoelastic constant and $\Delta \sigma_{\mathrm{ii}}$ is the change of the first stress invariant. Eqn.(7) is valid under the further assumptions of isotropic material and adiabatic behavior. This latter requirement is generally fulfilled by applying a rapidly varying load which usually consists in a cyclic load modulated above a suitable threshold frequency. In particular, Eqn.(7) shows that $\Delta \mathrm{T}$ is linearly related to $\Delta \sigma_{\mathrm{ii}}$ and therefore it is modulated at the same frequency of the applied load. This allows to obtain $\Delta \mathrm{T}$ from the sampled temperature by means of lock-in correlation or other narrow band-pass filtering procedures in the frequency domain. This practice, also identified as Thermoelastic Stress Analysis (TSA), brings in the further advantage of suppressing most of the environmental noise that might affect the measured temperature.

Therefore, TSA is able to provide the range of variation of the first stress invariant. Such stress metric can be used to retrieve stress intensity factors under both mode I and II at crack tips. One procedure for the evaluation of the range of variation of $\Delta \mathrm{K}_{\mathrm{I}}$ from $\Delta \mathrm{T}$ was introduced by Stanley and Chan in [32]. This allows the evaluation of $\Delta \mathrm{K}_{\mathrm{I}}$ from a simple linear regression, based on the following relationship:

$$
y=\left(\frac{3 \sqrt{3}}{4 \pi} T_{0}^{2} K_{T H}^{2} \Delta K_{I}^{2}\right) \frac{1}{\left(\Delta T_{\max }\right)^{2}}
$$

where $\Delta \mathrm{K}_{\mathrm{I}}$ is obtained from the slope of the line interpolating the values of $\mathrm{y}$ versus the experimental values of $\left(1 / \Delta \mathrm{T}_{\max }\right)^{2}$. In particular, $\Delta \mathrm{T}_{\max }$ represents the maximum value of the thermoelastic signal along a line running parallel to the crack line at a distance y. Eqn.(8) derives from modeling the near crack-tip stress field with the Westergaard stress equations arrested 
to first singular term. An advantage of the Stanley and Chan's extrapolation method compared to other least square fitting approaches is that an accurate knowledge of the crack tip position is not required.

Once $\mathrm{K}_{\mathrm{I}}$ is obtained from the maps of the thermoelastic signal $\Delta \mathrm{T}$ and from Eqn. (8), then $\mathrm{J}_{\mathrm{e}}$ can be obtained from Eqs. (6).

\section{Evaluating the plastic component of J-integral}

The total energy included in $\mathrm{V}_{\mathrm{c}}$ can be separated in its elastic, $\tilde{W}_{C C, e}$, and plastic, $\tilde{W}_{C C, p}$, components:

$$
\tilde{W}_{C C}=\int_{V_{c}} W_{C C} \cdot d V=\tilde{W}_{C C, e}+\tilde{W}_{C C, p}
$$

where

$$
\begin{aligned}
& \widetilde{W}_{C C, e}=\int_{V_{c}} W_{C C, e} \cdot d V \\
& \widetilde{W}_{C C, p}=\int_{V_{c}} W_{C C, p} \cdot d V
\end{aligned}
$$

In [29], a linear link was established between the plastic component of the strain energy density, $\tilde{W}_{C C, p}$, and the plastic component of the J-integral, Jmax,p:

$$
\frac{\widetilde{W}_{C C, p}}{t_{k}}=k_{p}\left(2 \alpha, n^{\prime}\right) \cdot J_{\max , p} \cdot R_{c}
$$

where $k_{p}\left(2 \alpha, n^{\prime}\right)$ is a constant depending on the notch opening angle and the cyclic hardening exponent.

Assuming the generalised Ramberg-Osgood law, according to which the strain is equal to the sum of its elastic and its plastic component, the plastic component of the strain energy density can be evaluated from the plastic strain component of Eqn. (12):

$$
W_{C C, p}=\frac{1}{1+n^{\prime}} \cdot \frac{\sigma_{e}^{\frac{1}{n^{\prime}}+1}}{\left(K^{\prime}\right)^{1 / n^{\prime}}}
$$

where $\sigma_{e}$ is the Von Mises stress and $\mathrm{K}^{\prime}$ is the cyclic strength coefficient.

For a Masing material [34], the plastic strain energy density per cycle, $\bar{W}$, can be evaluated from the Ramberg-Osgood relation according to Halford [35]:

$$
\bar{W}=\frac{1-n^{\prime}}{1+n^{\prime}} \cdot 2 \sigma_{e} \cdot 2\left(\frac{\sigma_{e}}{K^{\prime}}\right)^{\frac{1}{n^{\prime}}}
$$

Comparing Eqn. (12) and Eqn. (13), a link between $\overline{\mathrm{W}}$ and $\mathrm{W}_{\mathrm{CC}, \mathrm{p}}$ is obtained, as depicted in Fig. 4:

$$
\bar{W}=4\left(1-n^{\prime}\right) \cdot W_{C C, p}
$$

Substituting Eqn. (14), Eqn. (10b) becomes: 
$\widetilde{W}_{C C, p}=\frac{1}{4\left(1-n^{\prime}\right)} \int_{V_{c}} \bar{W} d V$

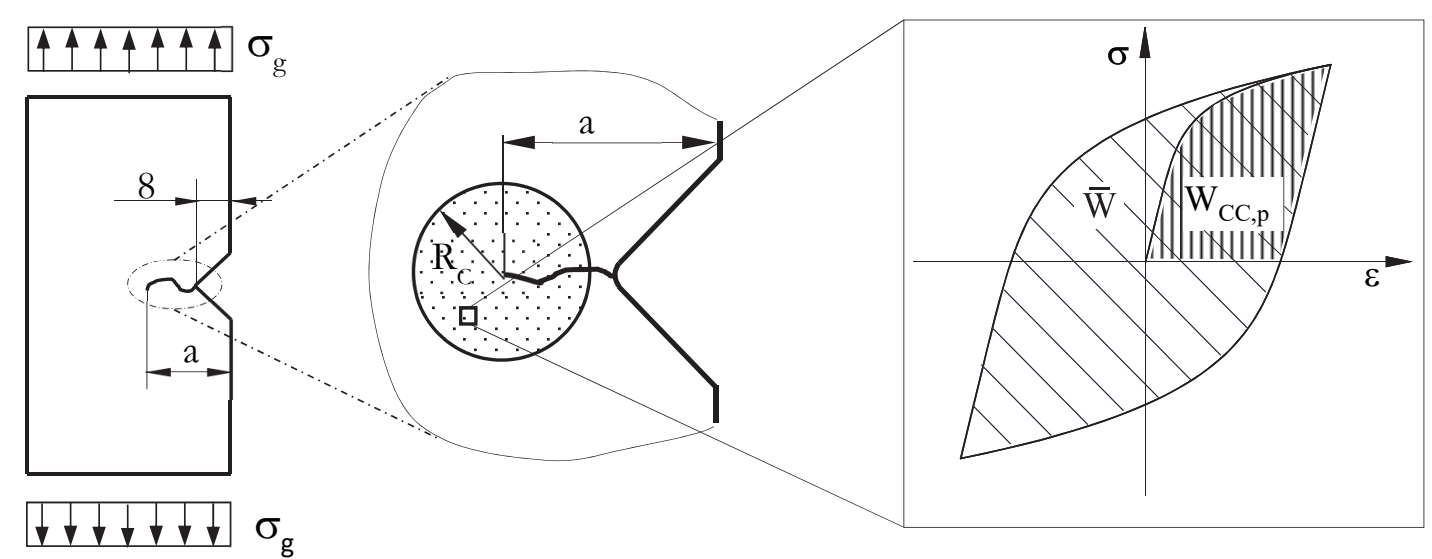

Figure 4: The plastic strain energy density per cycle, $\bar{W}$, and the plastic component of the strain energy density, $\mathrm{W}_{\mathrm{cc}, \mathrm{p}}$, at a point inside the material control volume.

There is now a body of experimental evidence that most part of the plastic strain energy per cycle $\bar{W}$ is converted into heat energy [36][37]. Letting $\overline{\mathrm{W}}=\overline{\mathrm{Q}}$ and using the definition of $\overline{\mathrm{Q}}^{*}$ (Eqn. (2)), Eqn. (15) can be written as follows:

$$
\widetilde{W}_{C C, p}=\frac{1}{4\left(1-n^{\prime}\right)} \cdot \bar{Q}^{*} \cdot V_{c}
$$

Finally, Eqn. (11) can be re-formulated to link the averaged heat energy and the plastic component of the J-integral:

$$
\overline{\mathcal{Q}}^{*}=\frac{4\left(1-n^{\prime}\right) \cdot k_{p}\left(2 \alpha, n^{\prime}\right)}{\pi \cdot R_{c}} \cdot J_{\max , p}
$$

Therefore, in the case of plane stress conditions, Eqn.(5) can be written in terms of maximum value of the J-integral as:

$$
J_{\max }=\frac{K_{I, \max }^{2}}{E}+\frac{\pi \cdot R_{c}}{4\left(1-n^{\prime}\right) \cdot k_{p}\left(2 \alpha, n^{\prime}\right)} \cdot \bar{Q}^{*}
$$

\section{MATERIAL, SPECIMEN GEOMETRY AND TEST METHODS}

onstant amplitude, fully-reversed $(\mathrm{R}=-1)$, load controlled crack propagation fatigue tests were carried out on
specimens prepared from 4-mm-thick, hot-rolled AISI 304L stainless steel sheets [28]. All tested specimens were
characterised by a 8-mm-deep crack starter, but different notch opening angle and notch tip radius, as shown in
Fig. 5. After polishing both specimens surfaces and mat black painting one of the specimen surfaces in order to increase
the emissivity, the evolution of material temperature during the fatigue tests was monitored by using a FLIR SC7000 infrared
camera. In order to improve the spatial resolution, a 30-mm-spacer ring was adopted, to achieve $23 \mu \mathrm{m} /$ pixel. On the other
hand, the Field of View (FoV) was reduced to 320x 256 pixels and the temperature field was acquired by positioning the
crack tip itself in the centre of the FoV to avoid vignetting. During the fatigue test, thermal images were recorded at given 
crack lengths with a frame rate facq $=200 \mathrm{~Hz}$ for a time window equal to $5 \mathrm{~s}\left(\mathrm{t}^{*}-\mathrm{t}_{\mathrm{s}}=5 \mathrm{~s}\right.$ in Fig. 3a), translating into 200x $5=1000$ acquired images. Subsequently, the temperature maps were processed by using the MotionByInterpolation tool to allow for the relative motion compensation between the fixed camera lens and the moving specimen due the sinusoidal applied load; the infrared image sequences were then analysed to perform the Thermoelastic Stress Analysis as well as to derive $\bar{Q}^{*}$.

In this work TSA was implemented off-line, i.e. after the thermal sequences had been acquired. Furthermore, no physical reference signal was acquired alongside with the temperature sampling, and a self-reference lock-in correlation had to be used. The procedure employed to implement TSA consisted in the following steps:

- Each sequence of thermograms, having a time span of $5 \mathrm{sec}$ and a frame rate of $200 \mathrm{~Hz}$, was imputed into Matlab, by using the Flir ResearchIR MAX v.3.4 exporting feature;

- The temperature-time signal from selected points at high stress locations was analysed in the frequency domain by applying the Discrete Fourier Transform (DFT), via the fft Matlab function. The analysis of the power spectrum from the DFT allowed to identify the frequency carrying the thermoelastic signal, $\mathrm{f}_{\mathrm{L}}$;

- The peak-to-peak amplitude $\Delta \mathrm{T}$ and the phase of the harmonic at the frequency $\mathrm{f}_{\mathrm{L}}$ were retrieved from each point, by applying a least square fitting of the experimental data with the following equation [38]:

$$
T(t)=a+b t+c \cos \left[2 \pi\left(f_{L}\right) t\right]+d \sin \left[2 \pi\left(f_{L}\right) t\right]+e \cos \left[2 \pi\left(2 f_{L}\right) t\right]+f \sin \left[2 \pi\left(2 f_{L}\right) t\right]
$$

where $\mathrm{t}$ is time and $\mathrm{c}, \mathrm{d}, \mathrm{e}, \mathrm{f}$ represent the in phase and in quadrature components of the thermoelastic signal and second harmonic amplitudes. The thermoelastic signal range and phase are readily obtained by:

$$
\Delta T=2 \sqrt{c^{2}+d^{2}} ; \text { phase }=\operatorname{atan}(\mathrm{d} / \mathrm{c})
$$

It is here reported that the values of $\Delta \mathrm{T}$ obtained with the above least square fitting procedure were also compared with the values of $\Delta \mathrm{T}$ obtained directly with the DFT fft Matlab function (implemented in [29]), yielding the same results.

The values of $\Delta T$ and phase are mapped and referred to as Thermoelastic Signal range and Thermoelastic Signal phase. The Thermoelastic constant $\mathrm{K}_{\mathrm{TH}}$, needed in Eqn. (8), had been evaluated experimentally for the material investigated, resulting $\mathrm{K}_{\mathrm{TH}}=3.75 \cdot 10^{-6} \mathrm{MPa}^{-1}$ [39]. Regarding the estimation of $\bar{Q}^{*}$, the spatial distribution of the pixel-by-pixel average temperature $T_{m}^{i}$ was calculated by averaging the available 1000 frames according to Eqn. (4) using the ALTAIR 5.90.002 commercial software; finally, the $\bar{Q}^{*}$ parameter was evaluated by applying Eqn. (3). After every acquisition of the aforementioned 1000 temperature frames, the fatigue test was stopped to allow the crack length to be measured by using a AM4115ZT Dino-lite digital microscope operating with a magnification ranging from 20x to 220x. The microscope monitored the specimen surface opposite to that stared by the infrared camera.

(a)

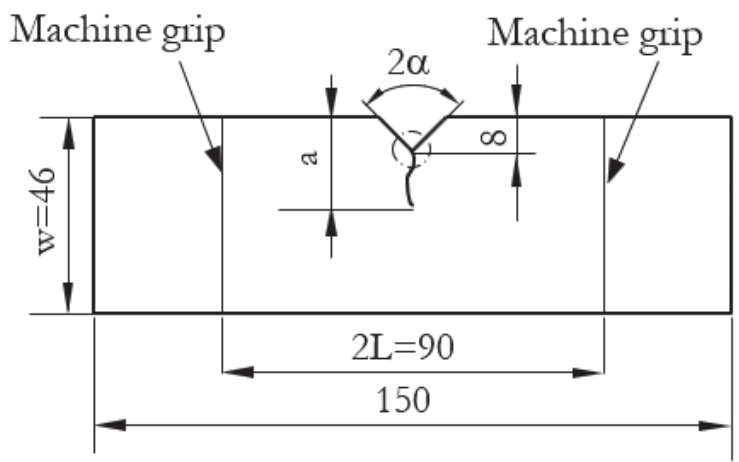

(b)

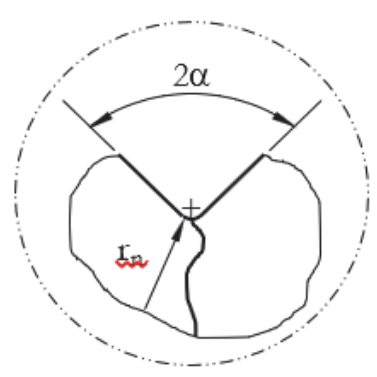

Figure 5: Specimen's geometry $\left(\mathrm{r}_{\mathrm{n}}=0.1 \mathrm{~mm}\right.$ for $2 \alpha=45^{\circ}, \mathrm{r}_{\mathrm{n}}=0.15 \mathrm{~mm}$ for $2 \alpha=90^{\circ}$; thickness is $4 \mathrm{~mm}$; dimensions in $\mathrm{mm}$ ) 


\section{EXPERIMENTAL EVALUATION OF THE J-INTEGRAL, BASED ON THERMAL MEASUREMENTS}

$\mathrm{I}$ $\mathrm{n}$ this section, the procedure for the evaluation of J-integral according to Eqn.(18) will be described. In view of this, the evaluation of the $k_{p}\left(2 \alpha, n^{\prime}\right)$ constant is needed. Therefore, two dimensional, plane stress, linear elastic as well as elastic-plastic finite element analyses of the tested specimens were performed in Ansys ${ }^{\circledR} 16.2$ commercial software, by using 4-node PLANE 182 element. The cyclic curve plotted in Fig. 6 was implemented, along with the Von Mises plasticity rule and the isotropic hardening behaviour. J-integral calculation was based on the domain integral approach implemented in Ansys ${ }^{\circledR}$. For more details of $\mathrm{FE}$ analyses, the reader is referred to [28]. Once evaluated $\mathrm{K}_{\mathrm{I} \text {,max }}$ and $\mathrm{J}_{\max }$ from purely elastic and elastic-plastic analyses, respectively, $\mathrm{J}_{\max , \mathrm{p}}$ was calculated from Eqn.(5). $\widetilde{W}_{a, p}$ evaluated in a control volume $\mathrm{R}_{\mathrm{c}}=0.52$ $\mathrm{mm}$ versus $\mathrm{J}_{\max , \mathrm{p}}$ is shown in Fig. 7 and it can be seen that a linear relationship can be proposed with $k_{p}\left(2 \alpha, n^{\prime}\right)=0.869$ in Eqn. (11) and a coefficient of correlation $\mathrm{R}^{2}=0.9976$.

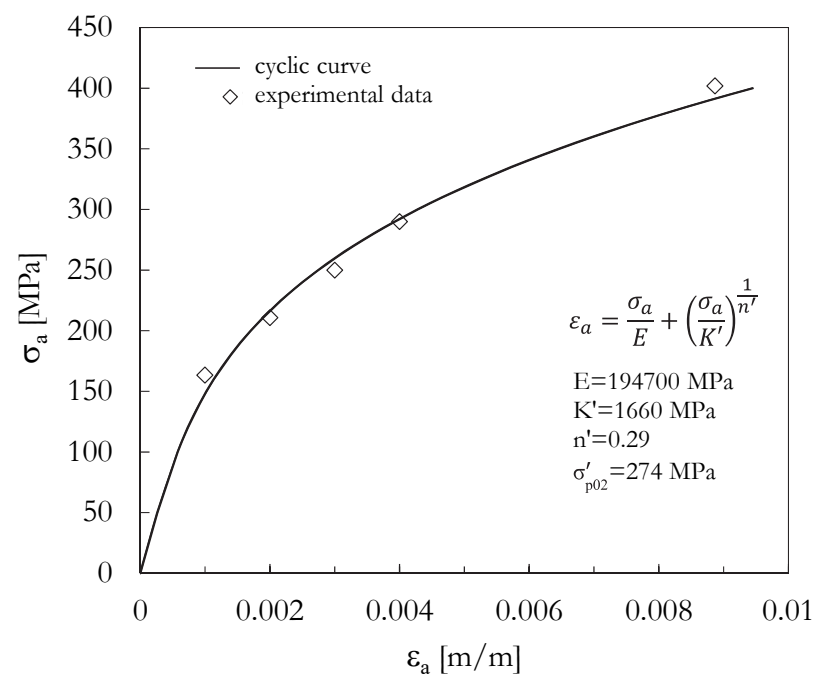

Figure 6: Cyclic stress-strain curve of the 4-mm-thick hot rolled AISI 304L stainless steel specimens [28].

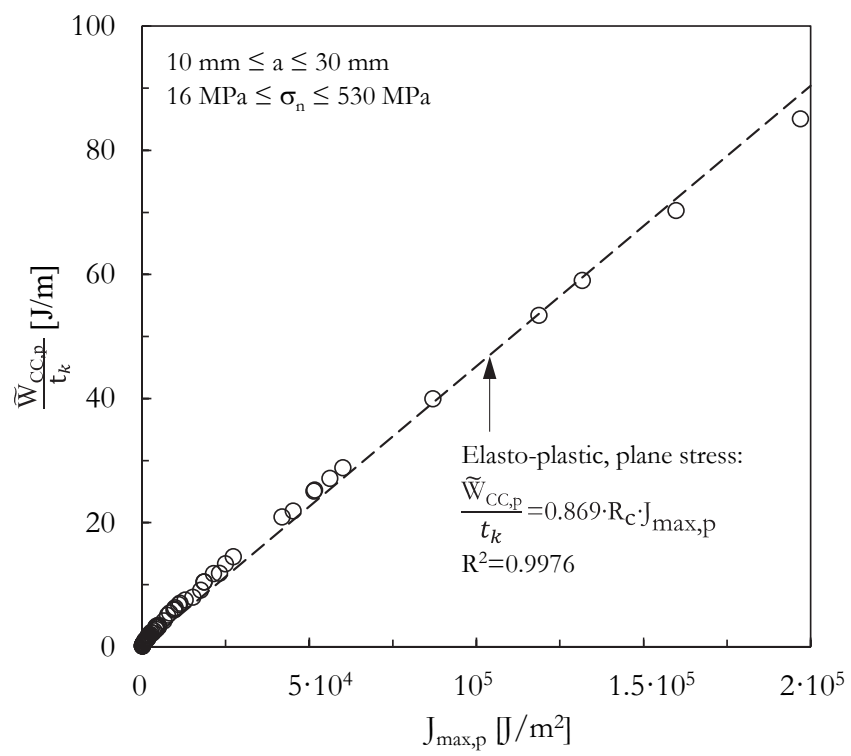

Figure 7: Plastic strain energy included in the control volume $V_{c}$ versus the plastic component of the J integral $\left(\sigma_{n}=\right.$ applied net-section stress). 
Once evaluated the $k_{p}\left(2 \alpha, n^{\prime}\right)$ constant, the experimental procedure for the J-integral evaluation can begin. In this paper, it will be described with the reference to a specimen of those tested during the crack propagation tests and highlighted in Fig. 8, by means of a red circle [28]. The selected sample has $r_{n}=0.1$ and $2 \alpha=45^{\circ}$, and the total crack length is a $=11.66 \mathrm{~mm}$, while the applied gross-section stress amplitude is $81 \mathrm{MPa}$ with a test frequency of $35 \mathrm{~Hz}$, translating into a $\Delta \mathrm{K}_{\mathrm{I}, \mathrm{FE}}$ evaluated by linear elastic finite element analysis equal to $35.4 \mathrm{MPa} \cdot \mathrm{m}^{0.5}$. Fig. 9 shows the temperature map averaged over 1000 frames, after the motion-compensation process.

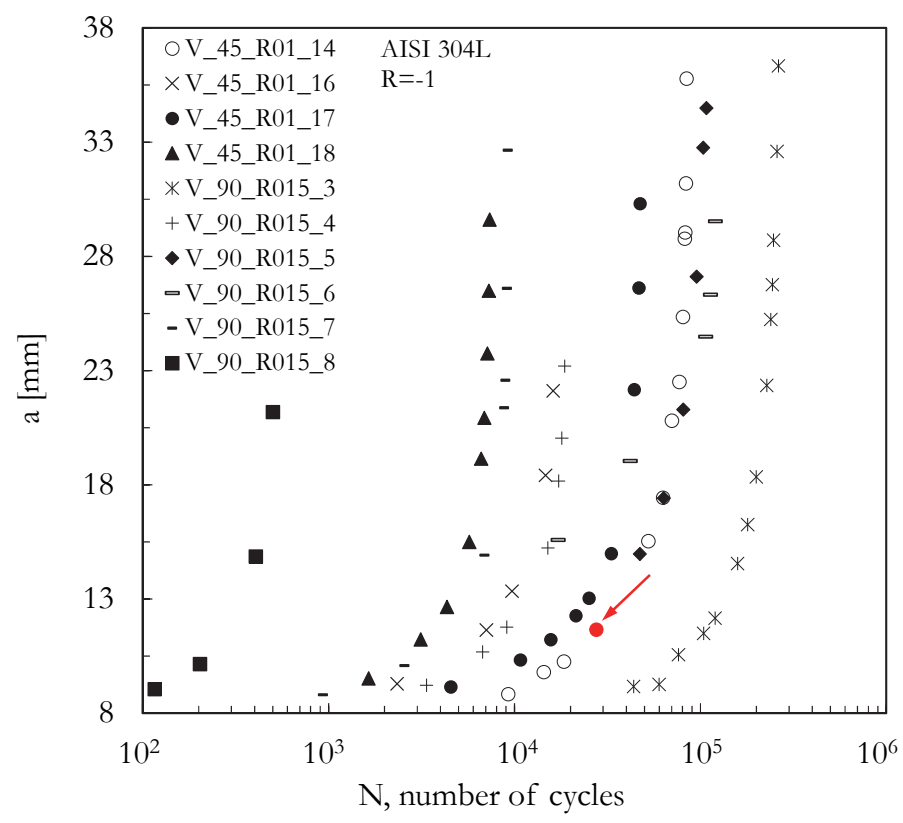

Figure 8: Crack propagation curves (red circle the specimen considered in this paper to describe the experimental procedure to evaluate the J-integral).
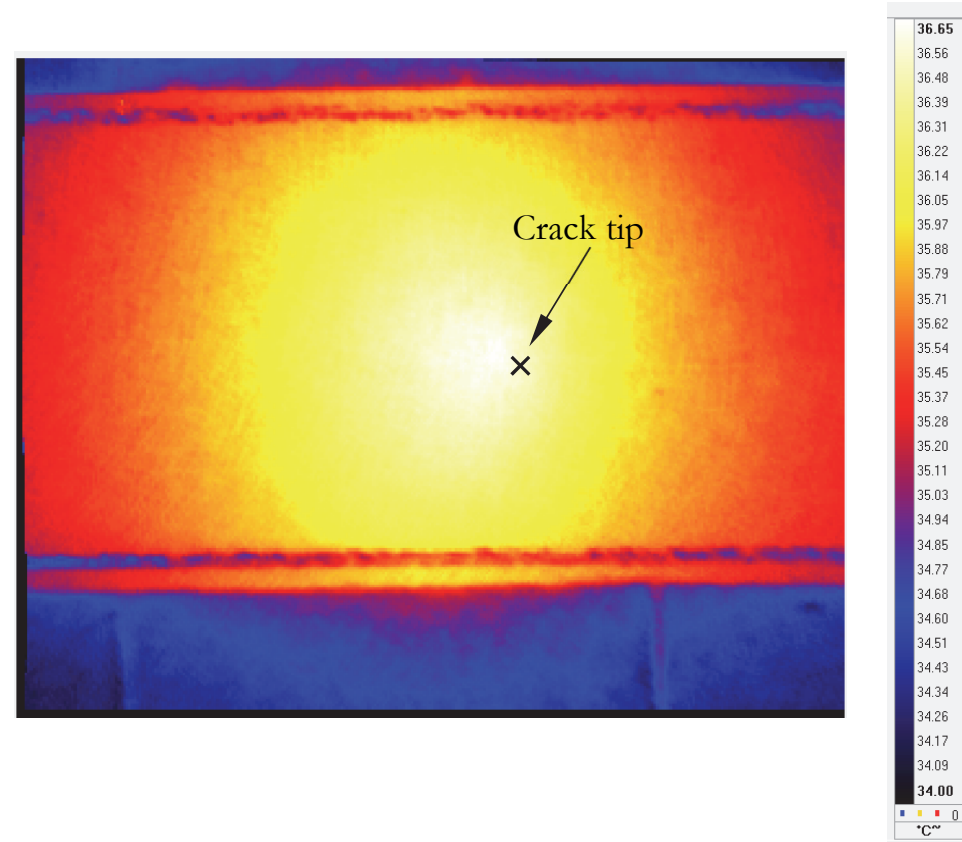

Figure 9: Average temperature field for a specimen having 11.66-mm-long crack, loaded at $\Delta \mathrm{K}_{\mathrm{I}, \mathrm{FE}}=35.4 \mathrm{MPa} \cdot \mathrm{m}^{0.5}, \mathrm{f}_{\mathrm{L}}=35 \mathrm{~Hz}$. The cross sign indicates the crack tip position as estimated by the optical microscope. 


\section{Evaluating the elastic component of J-integral by Thermoelastic Stress Analysis}

Examples of Thermoelastic Signal $\Delta \mathrm{T}$ and phase maps, obtained after the least square fitting procedure based on Eqn.(19), are reported in Figs. 10 and 11. Figs. 10b and 11b report also a close up view of the near crack tip zone, where the crack tip position, as measured by the optical microscope, is marked by a " $\mathrm{x}$ " sign. The points used in the linear regression procedure of Stanley-Chan are highlighted in fig. 12, which reports the plot of y $v s 1 /\left(\Delta \mathrm{T}_{\max }\right)^{2}$ according to Eqn.(8). The same points used in the linear regression are indicated by white dots in figs. $10 \mathrm{~b}$ and $11 \mathrm{~b}$.

(a)

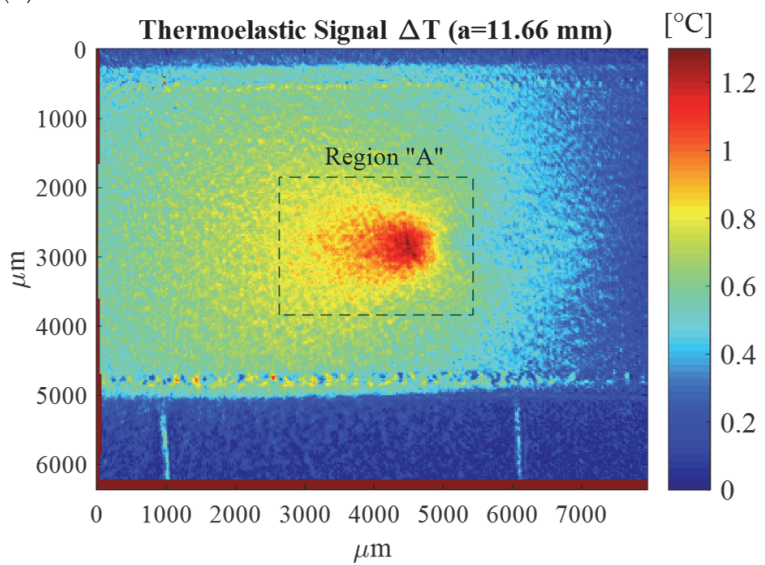

(b)

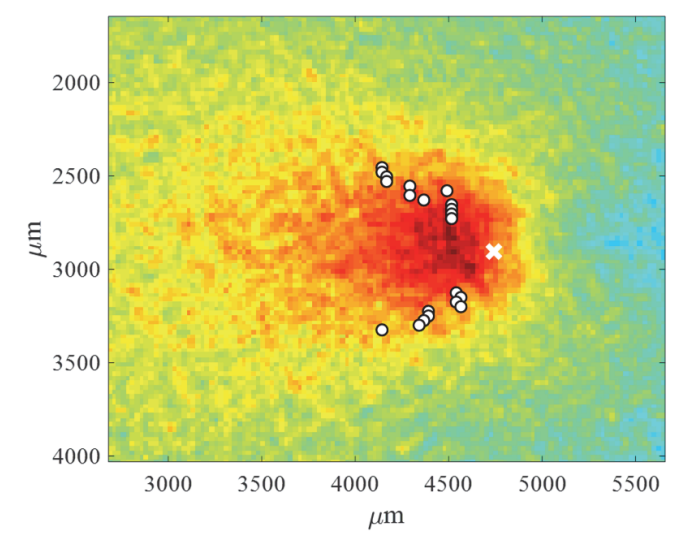

Figure 10: Map of thermoelastic signal range $\Delta \mathrm{T}$ (a) and detail of region " $\mathrm{A}$ " (b) (sample crack length $11.66 \mathrm{~mm}, \Delta \mathrm{K}_{\mathrm{I}, \mathrm{FE}}=35.4$ $\left.\mathrm{MPa} \cdot \mathrm{m}^{0.5}\right)$

(a)

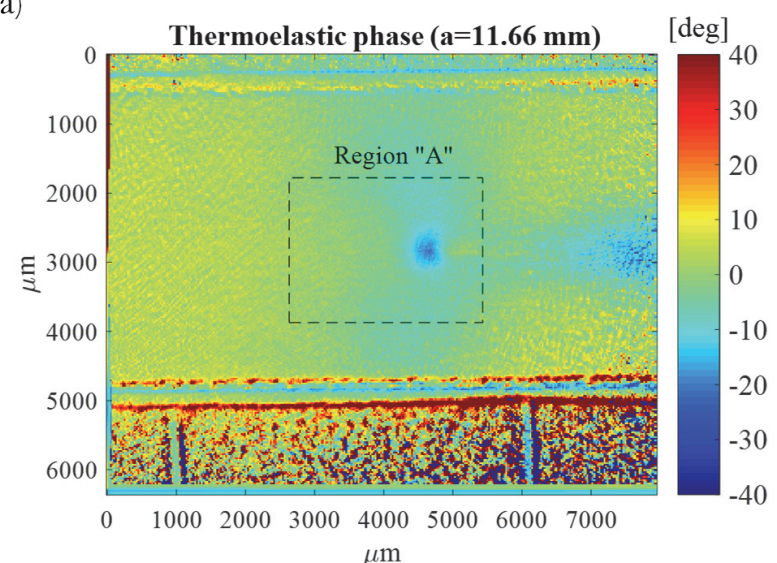

(b)

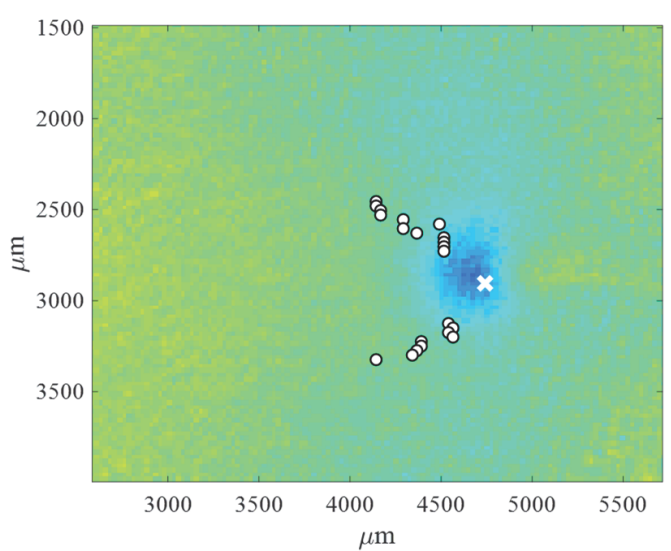

Figure 11: Map of thermoelastic phase (a) and detail of region "A" (b) (sample crack length $11.66 \mathrm{~mm}, \Delta \mathrm{K}_{\mathrm{I}, \mathrm{FE}}=35.4 \mathrm{MPa} \cdot \mathrm{m}^{0.5}$ ).

From Fig. 11 it is seen that the zero degree absolute reference for the phase map is, as routinely done in the literature for cracked specimens, attributed to the zone under traction ahead of the crack tip (i.e. in the ligament). It is noticed that the zone nearest to the crack tip presents a shift in phase. Such shift is widely reported in previous studies, and is mainly attributed to a loss of adiabaticity due to the steep stress gradients in the singularity dominated zone. The onset of dissipation effects and plasticity can be a further explanation for the departure from the expected thermoelastic laws behavior.

Fig. 11b in particular shows how the phase shifted zone is confined to an area next to the crack tip of size smaller than about $0.5 \mathrm{~mm}$. It is also observed that the points used in the linear regression of Eqn.(8) fall outside this out-of-phase zone. This gives some confidence that the loading frequency applied $(35 \mathrm{~Hz})$ is sufficient to guarantee the onset of adiabatic behavior in the areas where the thermoelastic signal is used for the quantitative evaluation of $\Delta \mathrm{K}_{\mathrm{I}}$. In the case of the example 
of Figs. 10, 11, it is in particular found $\Delta \mathrm{K}_{\mathrm{I}}=36.51 \mathrm{MPa} \cdot \mathrm{m}^{0.5}$. This value is about $3.2 \%$ higher than the value calculated by means of linear-elastic FE analysis. In [29], it was pointed out that, considering the analysed test conditions, values of $\Delta \mathrm{K}_{\mathrm{I}}$ have been found to differ from numerical values obtained from linear elastic FE analyses by generally less than $10 \%$. This level of approximation is comparable to that generally reported in the literature [40]. Having $\mathrm{K}_{\mathrm{I}}\left(\mathrm{K}_{\mathrm{I}}=\Delta \mathrm{K}_{\mathrm{I}} / 2\right)$, the elastic Jintegral can be evaluated according to Eqn.(6a), finding $J_{\max , \mathrm{e}}=1712 \mathrm{~J} / \mathrm{m}^{2}$.

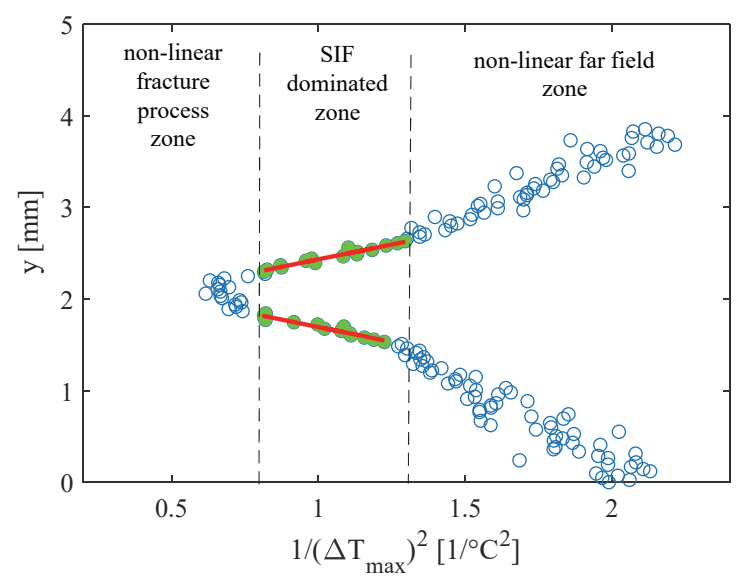

Figure 12: Plot of y versus $\left(1 / \Delta \mathrm{T}_{\max }\right)^{2}$ for specimen with crack length $11.66 \mathrm{~mm}$, and $\Delta \mathrm{K}_{\mathrm{I}, \mathrm{FE}}=35.4 \mathrm{MPa} \cdot \mathrm{m}^{0.5}$.

Evaluating the plastic component of J-integral by the heat energy loss

During the crack propagation fatigue tests, the crack length and the temperature field were measured at several times $t=t_{s}$, regularly distributed during each fatigue test after thermal equilibrium was achieved. As stated above, 1000 infrared images were acquired at each time $t_{s}$, then they were processed with the MotionByInterpolation algorithm and finally Eqn. (4) was applied. As an example, the temperature fields related to the sample shown in Fig. 8 for $\theta=0^{\circ}$ and $135^{\circ}$ (see Fig. 2) are shown in Fig. 13a and 13b, respectively. Red circles are the data considered for the evaluation of spatial temperature gradient at $\mathrm{r}=\mathrm{R}_{\mathrm{c}}$ and the specific heat flux $\bar{b}$ calculated along the boundary of $\mathrm{V}_{\mathrm{c}}$ is shown in Fig. 14. Then, $\bar{Q}^{*}$ was evaluated according to Eqn.(2), finding $\overline{\mathrm{Q}}^{*}=0.67 \mathrm{MJ} /\left(\mathrm{m}^{3} \cdot\right.$ cycle) and the plastic component of J-integral was finally calculated according to Eqn.(17), as $J_{\max , \mathrm{p}}=443 \mathrm{~J} / \mathrm{m}^{2}$, giving $\mathrm{J}=\mathrm{J}_{\max , \mathrm{e}}+\mathrm{J}_{\max , \mathrm{p}}=1712+443=2155 \mathrm{~J} / \mathrm{m}^{2}$.
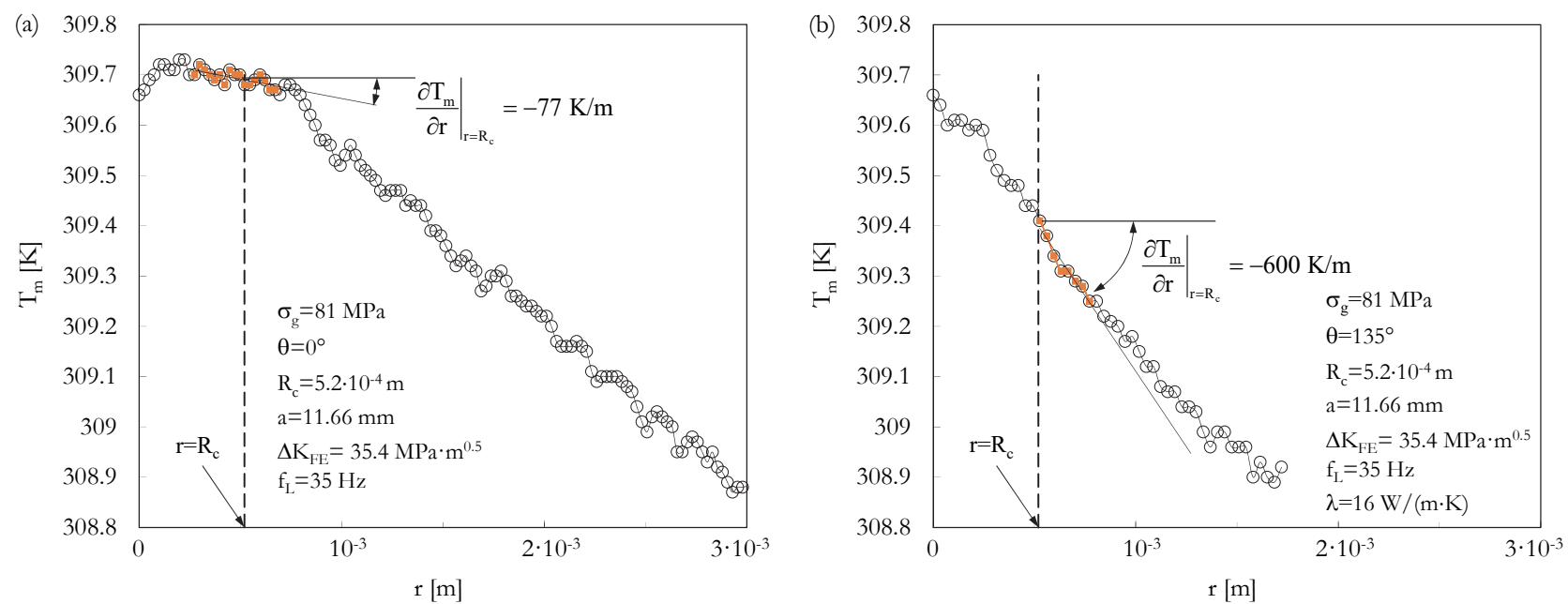

Figure 13: Experimental radial temperature profiles measured for $\theta=0^{\circ}$ (a) and $\theta=135^{\circ}$ (b) and evaluation of temperature gradient for $\mathrm{r}=\mathrm{R}_{\mathrm{c}}=0.52 \mathrm{~mm}$. 


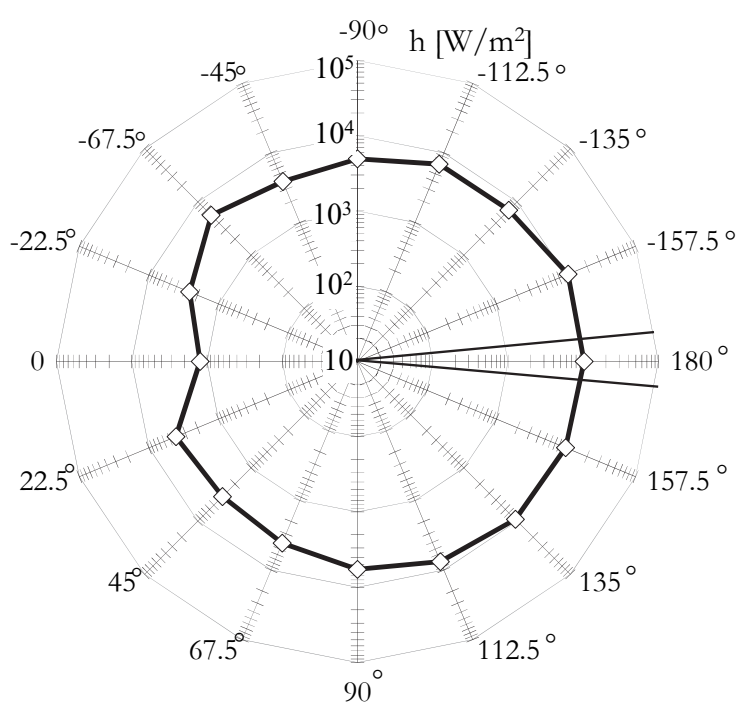

Figure 14: Specific heat flux distribution measured along the boundary of $\mathrm{V}_{\mathrm{c}}\left(\mathrm{R}_{\mathrm{c}}=0.52 \mathrm{~mm} ; \mathrm{a}=11.66 \mathrm{~mm} ; \Delta \mathrm{K}_{\mathrm{I}, \mathrm{FE}}=35.4 \mathrm{MPa} \cdot \mathrm{m}^{0.5}, \mathrm{f}_{\mathrm{L}}=35\right.$ $\mathrm{Hz}$ ).

\section{CRACK PROPAGATION DATA RATIONALIZED IN TERMS OF EXPERIMENTAL J-INTEGRAL}

7 he crack propagation data shown in Fig. 8 have been reanalyzed in terms of experimental J-integral in Fig. 15, along with the mean curve, the $10-90 \%$ survival probability scatter band and the scatter index $\mathrm{T}_{\mathrm{da} / \mathrm{dN}}$. Considering that the fatigue tests were carried out by imposing a load ratio equal to $-1(\mathrm{R}=-1)$, the $\Delta \mathrm{J}$ was assumed equal to $\mathrm{J}_{\max }$. The crack growth rates were synthesized in terms of $\Delta \mathrm{J}$ evaluated by means of $\mathrm{FE}$ analyses in Fig. 16. It can be seen that numerical results are very well fitted by the 10-90\% survival probability scatter band shown in Fig. 15.

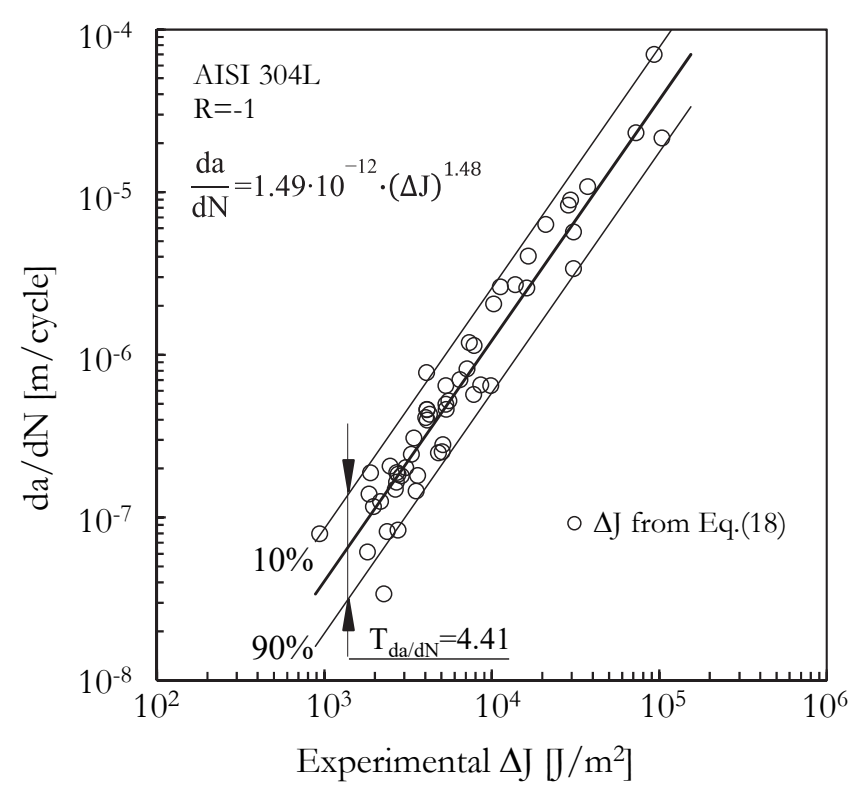

Figure 15: Crack propagation rates versus the J-integral range evaluated from temperature measurements. 


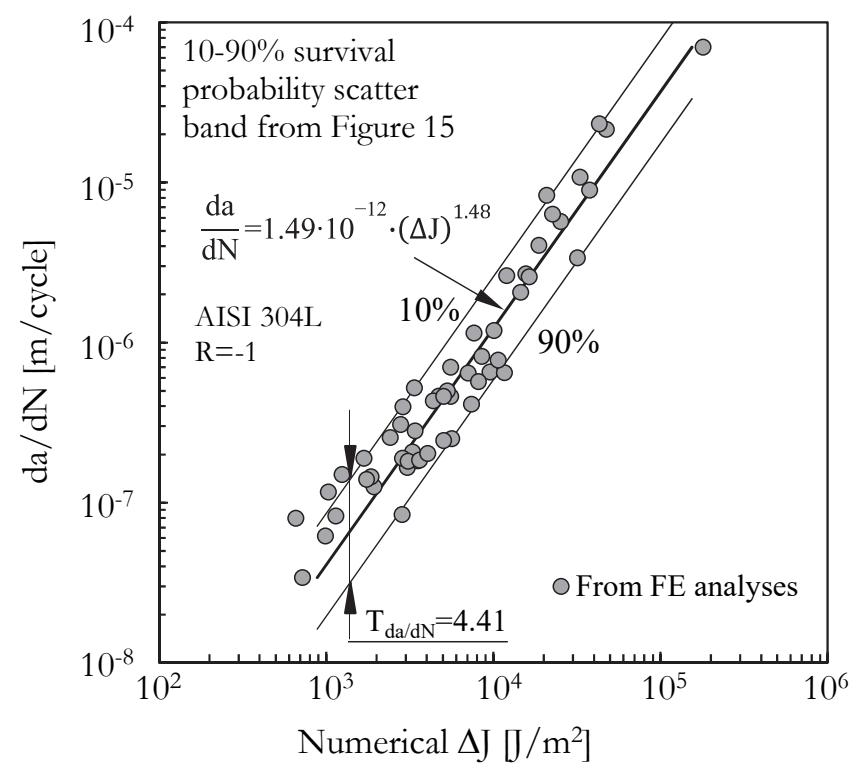

Figure 16: Comparison between finite element results and the scatter band fitted on the experimental values of $\Delta \mathrm{J}$ shown in Fig. 15.

\section{CONCLUSIONS}

I $\mathrm{n}$ this paper, an experimental procedure to calculate the J-integral during a fatigue test is presented. Such a technique is based on the measurement of the temperature distribution close to the tip of a propagating crack. The presented methodology calculates separately the elastic and the plastic components of J-integral and it requires adopting an infrared camera with high temperature resolution and spatial resolution. The elastic component is calculated from the Thermoelastic Stress Analysis and the plastic component from the specific heat loss per cycle averaged over a control volume of material. The proposed experimental technique has been applied to fatigue crack growth data generated from push-pull, axial fatigue tests of 4-mm-thick hot rolled AISI 304L stainless steel specimens. The crack propagation data were correlated in terms of range of the elastic-plastic J-integral. Finally, the experimental values of J were successfully compared to those calculated by performing elastic-plastic finite element analyses.

\section{REFERENCES}

[1] Rice, JR, Levy, N (1969). Local heating by plastic deformation at a crack tip, in Physics of strength and plasticity, A.S. Argon, ed. M.I.T Press, Cambridge, MA.

[2] Loos, PJ, Brotzen, FR (1983). Localized heat generation during fracture cyclically loaded steel. Metall Mater Trans A, 14A, pp. 1409-19. DOI: 10.1007/BF02664824.

[3] Crupi, V., Epasto, G., Guglielmino, E., Risitano, G. (2015). Analysis of temperature and fracture surface of AISI4140 steel in very high cycle fatigue regime. Theor Appl Fract Mech, 80, pp. 22-30. DOI: 10.1016/j.tafmec.2015.07.007.

[4] Kujawsky, D, Ellyin, F (1984). A fatigue crack propagation model. Eng Fract Mech, 20, pp. 695-04. DOI: 10.1016/00137944(84)90079-1.

[5] Ranganathan, N, Jendoubi, K, Benguediab, M, Petit, J. (1987). Effect of R ratio and DK level on the hysteretic energy dissipated during fatigue crack propagation. Scr Metall, 21, pp. 1045-49. DOI: 10.1016/0036-9748(87)90247-X

[6] Kuang, JH, Chen, YC. (1996). Crack initiation load characterization using the critical plastic energy. Eng Fract Mech, 53, pp. 571-80. DOI: 10.1016/0013-7944(95)00152-2.

[7] Skelton, RP, Vilhelmsen, T, Webster, GA. (1998). Energy criteria and cumulative damage during fatigue crack growth. Int J Fatigue, 20, pp. 641-49. DOI: 10.1016/S0142-1123(98)00027-9. 
[8] Klingbeil, NW. (2003). A total dissipated energy theory of fatigue crack growth in ductile solids. Int J Fatigue, 25, pp. 117-28. DOI: 0.1016/S0142-1123(02)00073-7.

[9] Daily, JS, Klingbeil, NW. (2004). Plastic dissipation in fatigue crack growth under mixed-mode loading. Int J Fatigue, 26, pp. 727-38. DOI: 10.1016/j.ijfatigue.2010.03.010.

[10] Mazari, M, Bouchouicha, B, Zemri, M, Banguediab, M, Ranganathan, N. (2008). Fatigue crack propagation analyses based on plastic energy approach. Comput Mat Sci, 41, pp. 344-49. DOI: 10.1016/j.commatsci.2007.04.016.

[11] Ranganathan, N, Chalon, F, Meo, S. (2008). Some aspects of the energy based approach to fatigue crack propagation. Int J Fatigue, 30, pp. 1921-29. DOI: 10.1016/j.ijfatigue.2008.01.010.

[12] Cojocaru, D, Karlsson, AM. (2009). Assessing plastically dissipated energy as a condition for fatigue crack growth. Int J Fatigue, 31, pp. 1154-62. DOI: 10.1016/j.ijfatigue.2008.12.009.

[13] Daily, JS, Klingbeil, NW. (2010). Plastic dissipation energy at a bimaterial crack tip under cyclic loading. Int J Fatigue 32, pp. 1710-23. DOI: 10.1016/j.ijfatigue.2010.03.010.

[14] Nittur, PG, Karlsson, AM, Carlsson, LA. (2014). Numerical evaluation of Paris-regime crack growth rate based on plastically dissipated energy. Eng Fract Mech, 124-125, pp. 155-66. DOI: 10.1016/j.engfracmech.2014.04.013.

[15] Ondracek, J, Materna, A. (2014). FEM evaluation of the dissipated energy in front of a crack tip under $2 \mathrm{D}$ mixed mode loading condition. Procedia Mater Sci, pp. 673-78. DOI: 10.1016/j.mspro.2014.06.111.

[16] Ranc, N, Palin-Luc, T, Paris, PC. (2011). Thermal effect of plastic dissipation at the crack tip on the stress intensity factor under cyclic loading. Eng Fract Mech, 78, pp. 61-72. DOI: 10.1016/j.engfracmech.2010.11.010.

[17] Ranc, N, Palin-Luc, T, Paris, PC, Saintier, N. (2014). About the effect of plastic dissipation in heat at the crack tip on the stress intensity factor under cyclic loading. Int J Fatigue, 58, pp. 56-65. DOI: 10.1016/j.ijfatigue.2013.04.012.

[18] Bhalla, KS, Zehnder, AT, Han, X. (2003). Thermomechanics of slow stable crack growth: closing the loop between experiments and computational modelling. Eng Fract Mech, 70, pp. 2439-58. DOI: 10.1016/S0013-7944(03)00006-7.

[19] Jones, R, Pitt, S. An experimental evaluation of crack energy dissipation (2006). Int J Fatigue, 28, pp. 1716-1724. DOI: 10.1016/j.ijfatigue.2006.01.009.

[20] Fedorova, A, Bannikov, MV, Plekhov, OA. (2012). Infrared thermography study of the fatigue crack propagation. Fracture and Structural Integrity, 21, pp. 46-53. DOI: 10.3221/IGF-ESIS.21.06.

[21] Bär, J, Seifert, S. (2014). Investigation of energy dissipation and plastic zone size during fatigue crack propagation in a high-alloyed steel. Procedia Mater Sci, 3, pp. 408-13. DOI: 10.1016/j.mspro.2014.06.068.

[22] Maletta, C, Bruno, L, Corigliano, P, Crupi, V, Guglielmino, E. (2014). Crack-tip thermal and mechanical hysteresis in Shape Memory Alloys under fatigue loading. Mat Sci Eng A-Struct, 616, pp. 281-87. DOI: 10.1016/j.msea.2014.08.007.

[23] Plekhov, O, Fedorova, A, Kostina, A, Panteleev, I. (2004). Theoretical and experimental study of strain localization and energy dissipation at fatigue crack tip. Procedia Mater Sci, 3, pp. 1020-25. DOI: 10.1016/j.mspro.2014.06.166.

[24] Breitbarth, E. and Besel, M. (2017). Energy based analysis of crack tip plasticity zone of AA2024-T3 under cycling loading, Int. J. Fatigue, 100, pp. 263-273. DOI: 10.1016/j.ijfatigue.2017.03.029.

[25] Palumbo, D., De Finis, R., Demelio, G.P., Galietti, U. (2017). Damage monitoring in fracture mechanics by evaluation of the heat dissipated in the cyclic plastic zone ahead of the crack tip with thermal measurements, Eng. Fract. Mech., 181, pp. 65-76. DOI: 10.1016/j.engfracmech.2017.06.017.

[26] Meneghetti, G. and Ricotta, M. (2016). Evaluating the heat energy dissipated in a small volume surrounding the tip of a fatigue crack, Int. J. Fatigue, 92, pp. 605-615. DOI: 10.1016/j.ijfatigue.2016.04.001.

[27] Izyumova, A. and Plekhov, O. (2014). Calculation of the energy J-integral in plastic zone ahead of a crack tip by infrared scanning, Fatigue Fract. Eng. Mater. Struct., 37, pp. 1330-1337. DOI: 10.1111/ffe.12202.

[28] Meneghetti, G and Ricotta, M. (2018). The heat energy dissipated in the material structural volume to correlate the fatigue crack growth rate in stainless steel specimens, Int. J. Fatigue, 115, pp. 107-119.

DOI: $10.1016 /$ j.ijfatigue.2018.07.037.

[29] Meneghetti, G., Ricotta, M., Pitarresi, G. (2019). Infrared thermography-based evaluation of the elastic-plastic J-integral to correlate fatigue crack growth data of a stainless steel, Int. J. Fatigue, 125, pp. 149-160.

DOI: $10.1016 /$ j.ijfatigue.2019.03.034.

[30] Rice, J.R. (1968). A path independent integral and the approximate analysis of strain concentration by notches and cracks, J. Appl. Mech., 35, pp. 379-386. DOI: 10.1115/1.3601206.

[31] Pitarresi, G., Patterson, E.A. (2003). A review of the general theory of thermoelastic stress analysis, J. Strain Anal. Eng. Des., 38, pp-405-17. DOI: 10.1243/03093240360713469. 
[32] Stanley, P. and Chan, W.K. (1986). The determination of stress intensity factors and crack-tip velocities from thermoelastic infra-red emissions, Proc. Int. Conf. Fatigue Eng. Mater. Struct. (I.Mech.E.), Sheffield, UK, 1986, p. 105114.

[33] Dowling, N.E. (2007). Mechanical behavior of materials, Pearson Prentice Hall.

[34] Masing, G. (1926). Eigenspannungen und Verfestigung beim messing. Procs. of the 2nd Int. Conf. of Applied Mechanics, Zurich, pp. 332-335.

[35] Halford, GR (1966). The energy required for fatigue. J. Mat, 1(1), pp. 3-18.

[36] Wan, VVC, MacLachlan, DW, Dunne, FPE (2014). A stored energy criterion for fatigue crack nucleation in polycrystals. Int J Fatigue, 68, pp. 90-102. DOI: 1 0.1016/j.ijfatigue.2014.06.001.

[37] Yao, Y, Wang, J, Keer, LM (2017). A phase transformation based method to predict fatigue crack nucleation and propagation in metals and alloys. Acta Mater, 127, pp. 241-251. DOI: 10.1016/j.actamat.2017.01.039.

[38] Krapez, J., Pacou, D., Gardette, G. (2000). Lock-in thermography and fatigue limit of metals. Quant Infrared Thermogr, 5, pp. 277-282. DOI: 10.21611/qirt.2000.051.

[39] Meneghetti, G, Ricotta, M, Atzori, B (2016). A two-parameter, heat energy-based approach to analyse the mean stress influence on axial fatigue behaviour of plain steel specimens. Int J Fatigue, 82, pp. 60-70. DOI: $10.1016 /$ j.ijfatigue.2015.07.028.

[40] Chrysochoos A, Louche H. An Infrared image process to analyse the calorific effects accompanying strain localization. Int J Eng Sci 2000; 38, 1759-1788. DOI: 10.1016/S0020-7225(00)00002-1. 